\title{
How to Treat Heart Failure in Patients with Cardiac Amyloidosis
}

\author{
Fabiana Goulart Marcondes-Braga ${ }^{\circledR}$ and Carlos Aurélio dos Santos Aragão ${ }^{(0)}$ \\ Instituto do Coração (InCor) - Hospital das Clínicas, Faculdade de Medicina, Universidade de São Paulo, São Paulo, SP - Brazil
}

\begin{abstract}
Amyloidosis is a multisystem disease characterized by deposition of fibrillar proteins in different tissues, the heart being one of the sites of amyloid deposition. Cardiac amyloidosis may present as a restrictive syndrome with symptoms of heart failure (HF). Treatment includes prognosis-modifying medications in HF; their optimization, however, is a challenge due to the frequent adverse effects in this population. Renin-angiotensin-aldosterone system blockade should be carried out using low doses because, due to autonomic dysfunction, these drugs may cause hypotension and fatigue. The use of diuretics is necessary to maintain euvolemic status and optimized preload; however, due to the ventricular restriction present in cardiac amyloidosis, these medications should be used with caution. In patients with amyloidosis who progress to advanced $\mathrm{HF}$, there are particularities in relation to indications for heart transplantation or long-term ventricular assist devices. The objective of this article is to review the treatment alternatives for HF in patients with cardiac amyloidosis.

Amyloidosis is a multisystem disease characterized by the deposition of fibrillar proteins with specific structural characteristics and a beta-pleated shape. The deposition of these proteins in the heart and the involvement of the autonomic nervous system make it challenging to manage heart failure (HF) in these patients. Given this scenario, This article aims to demonstrate how to manage HF in patients with cardiac amyloidosis.
\end{abstract}

\section{Approach to treatment of heart failure in patients with cardiac amyloidosis}

Data on HF treatment in patients with amyloidosis is lacking in randomized clinical trials. Therapeutic recommendations are based on expert opinions and experiences.

The deposition of fibrillar proteins in the myocardium leads to a reduction in the ventricular cavity, with consequent restricted filling, initially culminating in HF with preserved ejection fraction and finally HF with reduced

\section{Keywords}

Therapeutics; Heart Failure; Amyloidosis.

Mailing Address: Fabiana Goulart Marcondes-Braga •

Av. Dr. Enéas de Carvalho Aguiar, 44 - Bloco 1 -1ํ․ Andar. Postal Code: 05403-000, Cerqueira César, São Paulo, SP - Brazil.

E-mail: fgmarcondes@yahoo.com.br, fgmarcondes@gmail.com

Manuscript received October 04, 2021, revised manuscript October 15 2021, accepted October 15, 2021.

DOI: https://doi.org/10.36660/abchf.20210031 ejection fraction. This condition partially explains the difficulty in optimizing classic HF treatment. ${ }^{1}$

Orthostatic hypotension is frequently seen in $A L$ amyloidosis due to involvement of the autonomic nervous system. It complicates neurohormonal blockade, which has already been established in HF treatment. Medications such as corticosteroids with greater mineralocorticoid action (fludrocortisone), anticholinergics, and alpha-adrenergic agonists (midodrine) can be used to minimize postural hypotension. ${ }^{1}$ In addition, when autonomic polyneuropathy develops, the presence of hypotension can make it difficult to use diuretics due to labile preload. ${ }^{2}$

The main goal is to maintain euvolemia, which is a great challenge, because these patients may present themselves hypervolemia, euvolemia, and hypovolemia. The main drugs used for pulmonary and systemic decongestion are loop diuretics, which may be associated with mineralocorticoid receptor antagonists and even thiazide diuretics in situations of resistance to loop diuretics. It is important to underscore that hypervolemia may result in worsening of renal function as a consequence of cardiorenal syndrome due to renal venous congestion, and hypovolemia may lead to renal hypoperfusion due to reduced systolic volume, precipitating pre-renal acute kidney injury. ${ }^{2-3}$

The use of prognosis-modifying medications in HF is also a challenge due to the autonomic dysfunction that these patients very often develop Beta-blockers and renin-angiotensin-aldosterone system blockers are used sometimes, at low doses, given that these drugs can cause hypotension and fatigue. In other words, there is underutilization of medications that have been proven to promote reverse remodeling. ${ }^{4}$

Angiotensin II converting enzyme inhibitors, angiotensin II receptor blockers, and mineralocorticoid antagonists can be used safely, with gradual dose adjustment, in cases where there are no contraindications. Recently described drugs for treating $\mathrm{HF}$, such as neprilysin inhibitors, angiotensin II receptor antagonists, and SGLT2 inhibitors have not yet been tested, and there is no scientific evidence to support their use in patients with cardiac amyloidosis. ${ }^{2}$

The use of beta-blockers and non-dihydropyridine calcium channel blockers are usually not well tolerated, because, due to the low systolic ejection volume, these patients need heart rate to maintain cardiac output. In addition, the use of non-dihydropyridine calcium channel blockers in AL amyloidosis should be avoided, as they bind to amyloid fibrillar proteins, which can lead to advanced conduction disorders and even cardiogenic shock. ${ }^{2}$

Digitalis medications may be used cautiously to control heart rate and to improve cardiac performance with relative safety in cases of transthyretin and $\mathrm{AL}$ amyloidosis. However, it is important to underscore that the binding 
of these drugs with amyloid proteins increases the risk of digitalis toxicity. Thus, it is essential to monitor frequently by means of electrocardiogram and measurement of serum digoxin level. ${ }^{5-6}$

Specific treatment of AL amyloidosis with chemotherapy drugs may worsen preexisting cardiac dysfunction due to type I or type II cardiotoxicity. These drugs include cyclophosphamide, tyrosine kinase inhibitors, proteasome inhibitors, and checkpoint inhibitors. In view of this scenario, it is indispensable to monitor with cardiac markers, such as troponin and natriuretic peptides, which are already elevated in amyloidosis, as well as with Doppler echocardiography, preferably with assessment of global longitudinal strain, in order to early detect myocardial dysfunction due to cardiotoxicity ${ }^{7}$

In patients with amyloidosis who progress to advanced $\mathrm{HF}$, there are particularities in relation to indications for heart transplantation or long-term ventricular assist devices.

The reduced size of the left ventricular cavity and the frequent involvement of the right ventricle may be limitations to the indication of long-term ventricular assist devices. ${ }^{8-9}$

In relation to heart transplantation, patients with advanced HF should be evaluated for combined heartliver transplantation, given that the amyloid protein in transthyretin amyloidosis originates in the liver, and there are clinical reports of progression of cardiomyopathy and neuropathy in these patients, especially in those with the ValMet30 mutation. ${ }^{10}$

In patients with $\mathrm{AL}$ amyloidosis who progress to advanced $\mathrm{HF}$, heart transplantation may be indicated, provided that there is remission of the monoclonal gammopathy by means of chemotherapy drugs or bone marrow transplantation. ${ }^{11}$

The Figure 1 shows the difficulties and special care in the use of guideline directed medical treatment for HFrEF to patients with cardiac amyloidosis.

\section{Conclusion}

The treatment that has already been well established for HF in patients with cardiac amyloidosis is challenging. It must be adapted to the structural and pathophysiological characteristics of the disease. It is important to highlight that, in addition to treating HF, specific treatment of amyloidosis is indispensable to increasing survival and quality of life in these patients.

\section{Author contributions}

Conception and design of the research: MarcondesBraga F, Aragão CAS. Acquisition of data:Aragão CAS. Analysis and interpretation of the data: Marcondes-Braga F, Aragão CAS. Writing of the manuscript: MarcondesBraga F, Aragão CAS. Critical revision of the manuscript for intellectual content: Marcondes-Braga F. Supervision / as the major investigador: Marcondes-Braga F.

\section{Potential Conflict of Interest}

No potential conflict of interest relevant to this article was reported.

\section{Sources of Funding}

There were no external funding sources for this study.

\section{Study Association}

This study is not associated with any thesis or dissertation work.

\section{Ethics approval and consent to participate}

This article does not contain any studies with human participants or animals performed by any of the authors.

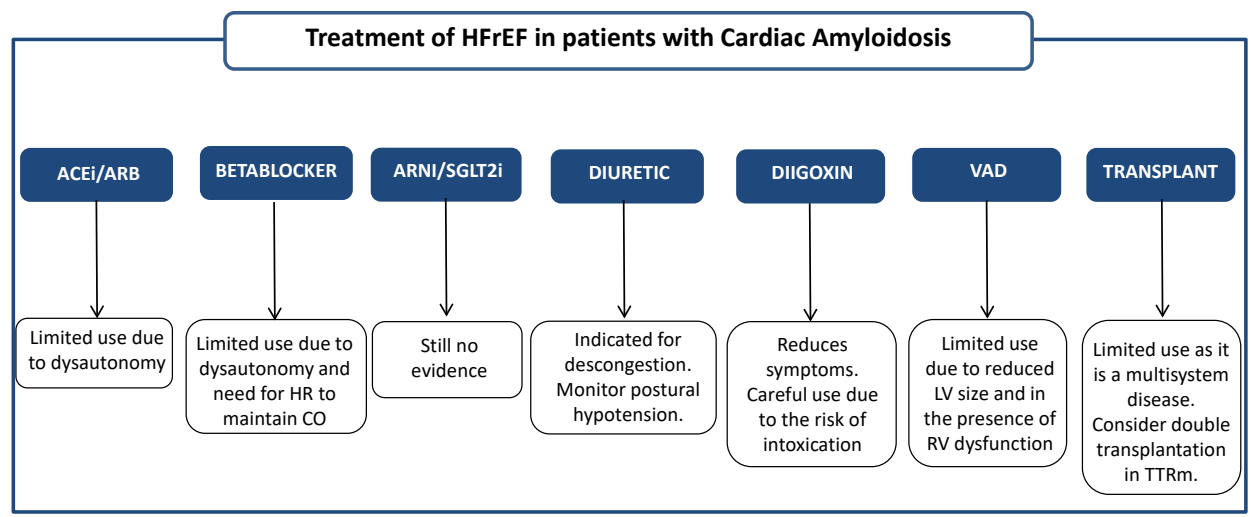

Figure 1 - Treatment of HFrEF in patients with Cardiac Amyloidosis. HFrEF: heart failure with reduced ejection fraction; ACEi: angiotensin conversor enzyme inhibitor; ARB: angiotensin receptor blocker; ARNI: angiotensin receptor and neprilisin inhibitor; SGLT2i: SGLT2 inhibitor; VAD: ventricular assist device; CO: cardiac output; RV: rigth ventricule; TTR: transtiretin. 


\section{Review Article}

\section{References}

1. Ritts AJ, Cornell RF, Swiger K, Singh J, Goodman S, Lenihan DJ. Current Concepts of Cardiac Amyloidosis: Diagnosis, Clinical Management, and the Need for Collaboration. Heart Fail Clin. 2017;13(2):409-16. doi: 10.1016/j. hfc.2016.12.003.

2. Pollak A, Falk RH. Left Ventricular Systolic Dysfunction Precipitated by Verapamil in Cardiac Amyloidosis. Chest. 1993;104(2):618-20. doi: 10.1378/chest.104.2.618.

3. Mohty D, Damy T, Cosnay P, Echahidi N, Casset-Senon D, Virot P, et al. Cardiac Amyloidosis: Updates in Diagnosis and Management. Arch Cardiovasc Dis. 2013;106(10):528-40. doi: 10.1016/j.acvd.2013.06.051.

4. Shin SC, Robinson-Papp J. Amyloid Neuropathies. Mt Sinai J Med. 2012;79(6):733-48. doi: 10.1002/msj.21352.

5. Donnelly JP, Sperry BW, Gabrovsek A, Ikram A, Tang WHW, Estep J, et al. Digoxin Use in Cardiac Amyloidosis. Am J Cardiol. 2020;133:134-38. doi: 10.1016/j.amjcard.2020.07.034.

6. DonnellyJP, Gabrovsek A, Sperry BW, Young L, EstepJ, TangWW, etal. Digoxin Use in Cardiac Amyloidosis. J. Card. Fail. 2019;25(8):25-6. doi: 10.1016/j. cardfail.2019.07.070.
7. Sperry BW, Ikram A, Hachamovitch R, Valent J, Vranian MN, Phelan D, et al. Efficacy of Chemotherapy for Light-Chain Amyloidosis in Patients Presenting with Symptomatic Heart Failure. J Am Coll Cardiol. 2016;67(25):2941-8. doi: 10.1016/j.jacc.2016.03.593.

8. Topilsky Y, Pereira NL, Shah DK, Boilson B, Schirger JA, Kushwaha SS, et al. Left Ventricular Assist Device Therapy in Patients with Restrictive and Hypertrophic Cardiomyopathy. Circ Heart Fail. 2011;4(3):266-75. doi: 10.1161/CIRCHEARTFAILURE.110.959288.

9. Grupper A, Park SJ, Pereira NL, Schettle SD, Gerber Y, Topilsky Y, et al. Role of Ventricular Assist Therapy for Patients with Heart Failure and Restrictive Physiology: Improving Outcomes for a Lethal Disease. J Heart Lung Transplant. 2015;34(8):1042-9. doi: 10.1016/j.healun.2015.03.012.

10. Suhr OB, Herlenius G, Friman S, Ericzon BG. Liver Transplantation for Hereditary Transthyretin Amyloidosis. Liver Transpl. 2000;6(3):263-76. doi: 10.1053/lv.2000.6145.

11. Hasserjian RP, Goodman HJ, Lachmann HJ, Muzikansky A, Hawkins PN. Bone Marrow Findings Correlate with Clinical Outcome in Systemic AL Amyloidosis Patients. Histopathology. 2007;50(5):567-73. doi: 10.1111/j.1365-2559.2007.02658.x. 